\title{
STUDY OF THE BALANCE STABILITY OF YOGA EXERCISES PRACTITIONERS
}

\author{
Vladimir Angelov, Ognian Tishinov, \\ Evald Albert
}

\author{
National Sports Academy "Vassil Levski". Sofia, Bulgaria
}

\begin{abstract}
Yoga is an ancient system with complex effect on humans. The aim of this study was to determine the effect of the different structural groups of yoga exercises on the balance abilities of the practitioners. The object of the research was the balance stability. The subject of the study was the value and frequency fluctuations of COG during the execution of the control balance exercise. A contingent of the study was a group of 25 practitioners.

The basic scientific method used for the realization of this research is the method of posturographic analysis. It allows to determine the dynamics of COG. The practical experiment includes measurments after every training impact with various structural groups of yoga exercises.

The results concern the movements of the projection of COG. The collected data is presented through tables and graphs. The results reflect the dynamics of the COG during the execution of the balance exercise. Thus, this paper established the effect of the impact of various yogic exercises on the balance stability of the participants.

Keywords: postural stability, stabilogram analysis, posturographic platform, balance abilities, yoga asana.

\section{INTRODUCTION}

Balance stability is a psychomotor quality with a great importance for the human motor activity. It is a prerequisite for the successful realization of the athletes in all sports. This characteristic of balance stability has directed our attention to study this quality in the conditions of yoga practice.

Yoga is an ancient system with complex effects on the human - physical, mental and spiritual. Its wide-ranging and beneficial influence on the body is wellknown. In this article, the attention is focused to the yogic asanas as means for developing the physical component of the Human system.

According to the hypothesis of the study, the practice of different groups of yogic exercises generates inhomogeneous traces of reflections related to the motor functions of the practitioners. We assume that the physiological states after execution of various structural groups of yogic asanas will influence in a different way the balance abilities of the practitioners.

By their nature, asanas can be defined as static exercises with a predominant stretching effect. Their great diversity implies the necessity of their systematization. Figure №1 shows an exemplary classification of yogic asanas according to the direction of their impact.
\end{abstract}




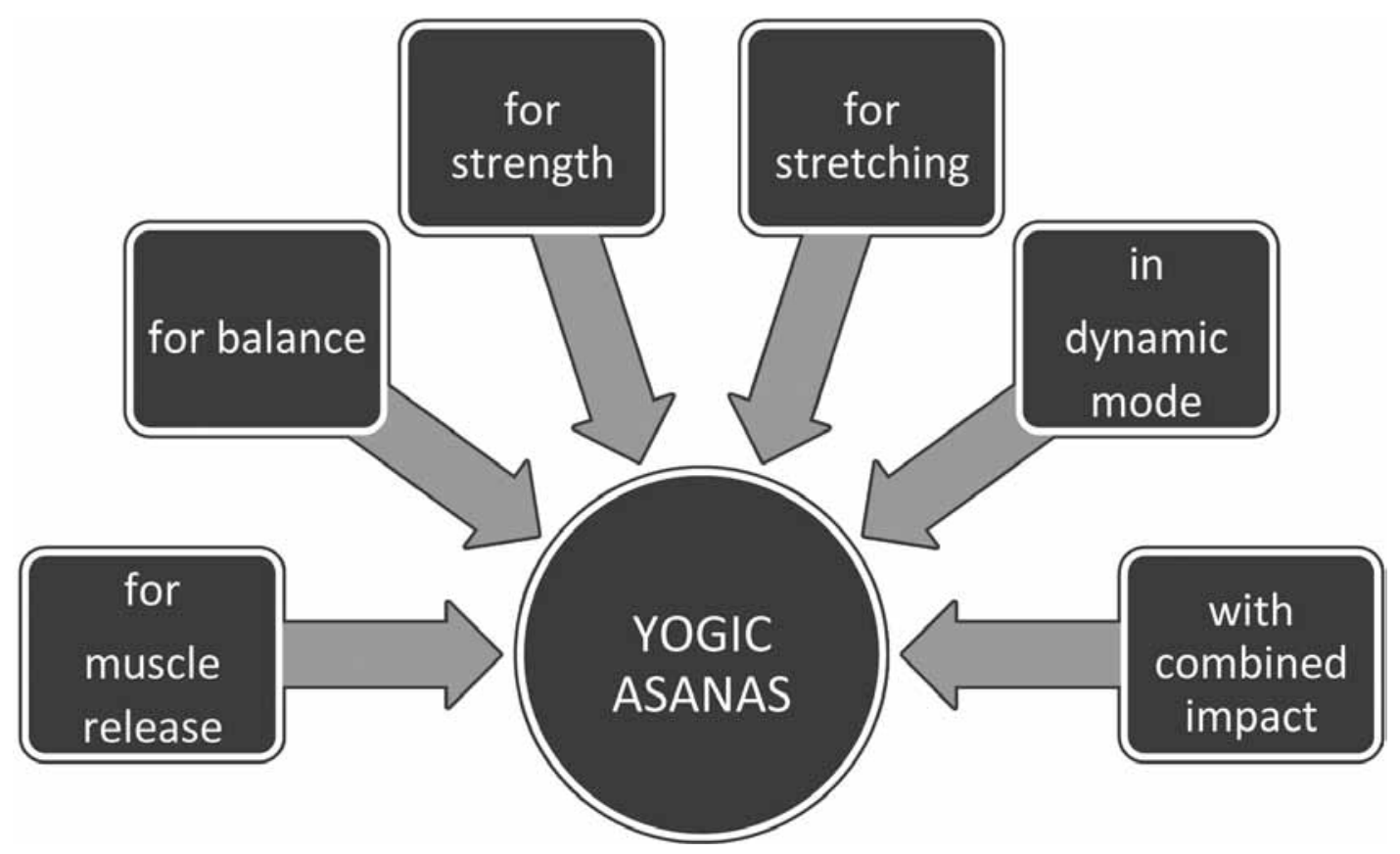

Figure 1. Classification of yogic asanas according to the orientation of their impact.

Numerous information sources were examined for the realization of the study. Their review showed that among the observed effects from the yogic asanas performance there is no evidence for their influence over balance stability. This finding is confirmed by authors such as Farhi D. (2001), Iyengar B. K. S. (1995), Kaminoff L, Matthews A. (2011), Long R. (2009), Smith J., Hall D., Gibbs B. (2005), Stephens M. (2010), Albert M. (2015). This provoked our interest to explore this problem. An additional reason for the research was our idea to use an apparatus method to establish the balance stability. The reviewed literature showed that similar methods were used by other specialists, including Bizzo G., Guillet M., Patat A. et al. (1985), Gagey P. M., Weber B. (1995), Gurfinkel V. S., Kots Y. M., Shik M. L. (1965), Kapteyn T. S., Bles W., Njiokiktjien Ch. J. et al. (1983), Skvortsov D.V. (2000).
The aim of this study is to determine the effect of practicing various structural groups of yoga exercises on the balance abilities of the practitioners. The following tasks for achievement of the purpose were solved:

A classification of yogic asanas according to the direction of the impact was made.

An experimental group and a control balance exercise were created to assess the balance abilities with the use of the method of posturographic analysis.

A practical experiment was carried out with the use of a posturographic platform and application of a training impact with five different groups of asanas.

The collected data were systematized and analyzed.

The object of the research is balance stability. The subject of the study is the value of the amplitude and the frequency fluctuations of the COG during the execu- 
tion of the control balance exercise. The study was done among a group of students from NSA "Vassil Levski" with major "Acrobatics and Trampoline".

This publication is intended for a wide range of sports experts. Its design is focused on exploring the effects of yogic asanas that have not been identified yet. This makes the research important and original. The proof of the main thesis and hypothesis of the survey would determine the significance of this article for the sports practice.

\section{METHODS}

The basic research method for the realization of this work is the method of posturographic analysis. It allows us to determine the dynamics of the COG while participants retain the balance position. The control balance exercise is shown in figure №2.

The method of stabilogram analysis is essentially an apparatus method. It is carried out using a posturographic platform, which was invented by eng. Ognian Tishinov in 1983. It works on the principle of a pressure. The signals are captured by sensors, converted into digitals and recorded into a computer device. Fig. 3 shows an exemplary stabilogram. A specialized software to analyze the results was developed (Tishinov, O., 2017). The software allows reporting the value of the amplitude displacement and the frequency of fluctuations of the projection of the $\mathrm{COG}$ in relation to the supporting area.

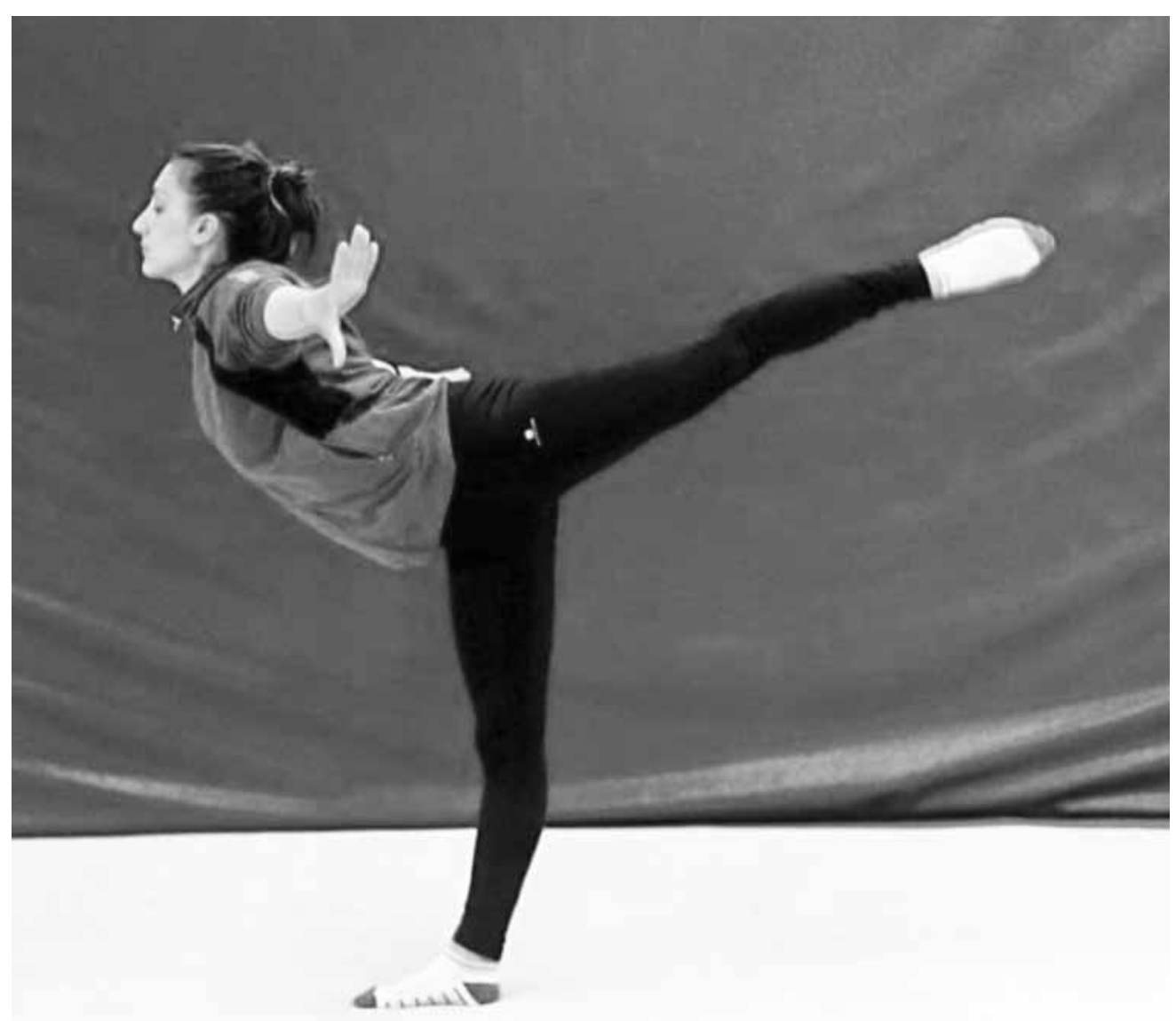

Figure 2. A control balance exercise 
The amplitude of the displacement gives information about the end values of the balance fluctuations related to keeping the projection of the COG within the boundary of the supporting area. The frequency of fluctuations informs about the speed of the compensatory actions related to the internal control through the proprioreceptors of the motor apparatus. Thanks to the balance coefficient created by the authors of this work, results from different measurements can be compared. The balance coefficient represents the ratio between the amplitude of displacement and the frequency of fluctuations of the COG.

The practical experiment was realized on a contrasting principle, alternating measurement and training impact. Six series of measurements were performed. Each series included an athlete's holding the control balance exercise on the stabilogram platform for 40 seconds. The first measurement was made at the beginning of the research before the participants performed the yoga exercises. It was followed by a training consisting of five groups of asanas. The duration of the workload in each group was $5 \mathrm{~min}$. It included 10 asanas. After each training session, a rest of 3 minutes was given, followed by a measurement of the balance stability through the control exercise performed on the stabilogram platform.

The groups of yoga exercises used were applied in the following sequence: asanas for muscle release, strength asanas, stretching asanas, asanas in dynamic mode, asanas for balance. The survey was done among 25 participants.

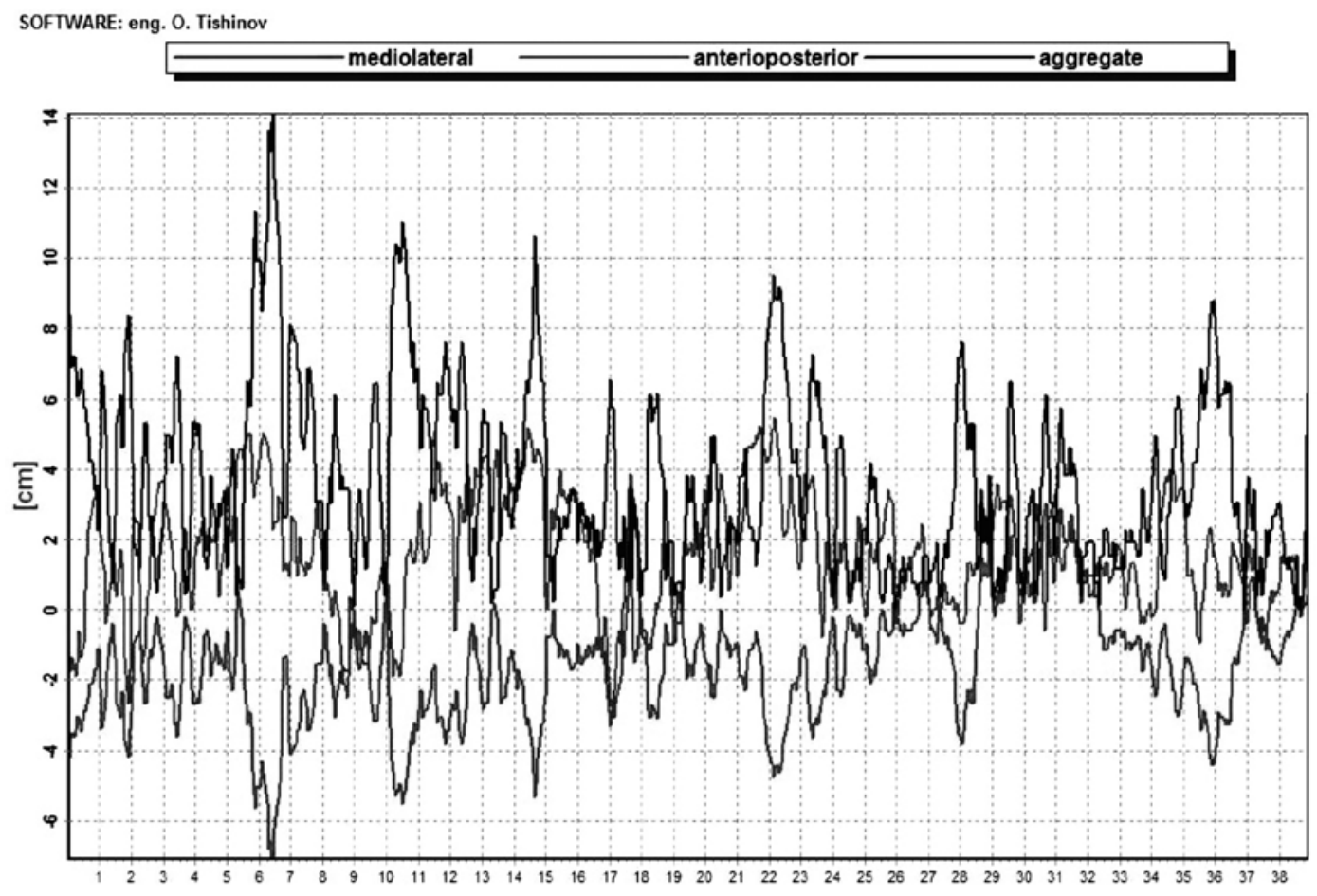

Figure 3. An exemplary stabilogram 


\section{RESULTS}

The research of the balance stability was carried out with the help of a posturographic platform and specialized software. The apparatus configuration allows registration of the collected data from the measurement and their graphical expression by stabilograms (Figure 3). On this basis, three basic parameters were established and analyzed: amplitude of the COG deviation, rate of the COG fluctuations and balance coefficient. The data collected were systematized and statistically processed using the variance analysis method (Tables 1 and 2).

In summary, the results are presented in the diagram (Fig. 4.)

Table 1. Systematization of the collected data from the variance analysis method in the I, II and III measurement.

\begin{tabular}{|c|c|c|c|c|c|c|c|c|c|}
\hline Parameters & $\underset{1}{\text { Amplitude }}$ & $\begin{array}{c}\text { Frequency } \\
1\end{array}$ & $\begin{array}{c}\text { Coefficient } \\
1\end{array}$ & $\begin{array}{c}\text { Amplitude } \\
2\end{array}$ & $\begin{array}{c}\text { Frequency } \\
2\end{array}$ & $\begin{array}{c}\text { Coefficient } \\
2\end{array}$ & $\begin{array}{c}\text { Amplitude } \\
3\end{array}$ & $\begin{array}{c}\text { Frequency } \\
3\end{array}$ & $\begin{array}{c}\text { Coefficient } \\
3\end{array}$ \\
\hline Min & 3,47 & 3,68 & 0,84 & 2,60 & 3,87 & 0,48 & 3,10 & 3,49 & 0,66 \\
\hline $\operatorname{Max}$ & 20,32 & 5,24 & 5,48 & 10,60 & 5,46 & 2,55 & 12,40 & 5,19 & 3,38 \\
\hline $\mathbf{R}$ & 16,85 & 1,56 & 4,64 & 8,00 & 1,59 & 2,07 & 9,30 & 1,70 & 2,72 \\
\hline $\mathbf{X}$ & 9,37 & 4,27 & 2,30 & 5,69 & 4,56 & 1,32 & 6,52 & 4,29 & 1,63 \\
\hline S & 5,27 & 0,50 & 1,51 & 3,35 & 0,58 & 0,86 & 3,50 & 0,61 & 1,05 \\
\hline V & $56 \%$ & $12 \%$ & $66 \%$ & $59 \%$ & $13 \%$ & $65 \%$ & $54 \%$ & $14 \%$ & $64 \%$ \\
\hline As & 1,32 & 0,85 & 1,46 & 0,53 & 0,51 & 0,45 & 0,56 & 0,32 & 0,67 \\
\hline Ex & 2,24 & 1,07 & 2,33 & $-1,77$ & $-1,39$ & $-1,84$ & $-1,14$ & $-1,27$ & $-1,06$ \\
\hline
\end{tabular}

Table 2. Systematization of the collected data from the variance analysis method in the IV, V and VI measurement.

\begin{tabular}{|c|c|c|c|c|c|c|c|c|c|}
\hline Parameters & $\begin{array}{c}\text { Amplitude } \\
4 \\
\end{array}$ & $\begin{array}{c}\text { Frequency } \\
4 \\
\end{array}$ & $\begin{array}{c}\text { Coefficient } \\
4 \\
\end{array}$ & $\begin{array}{c}\text { Amplitude } \\
5 \\
\end{array}$ & $\begin{array}{c}\text { Frequency } \\
5 \\
\end{array}$ & $\begin{array}{c}\text { Coefficient } \\
5 \\
\end{array}$ & $\begin{array}{c}\text { Amplitude } \\
6\end{array}$ & $\begin{array}{c}\text { Frequency } \\
6 \\
\end{array}$ & $\begin{array}{c}\text { Coefficient } \\
6 \\
\end{array}$ \\
\hline Min & 4,71 & 3,90 & 0,85 & 2,08 & 3,51 & 0,35 & 4,88 & 3,23 & 1,05 \\
\hline $\operatorname{Max}$ & 13,60 & 9,97 & 2,38 & 10,69 & 5,88 & 2,45 & 14,40 & 5,53 & 4,23 \\
\hline $\mathbf{R}$ & 8,89 & 6,07 & 1,53 & 8,61 & 2,37 & 2,10 & 9,52 & 2,30 & 3,18 \\
\hline $\mathbf{X}$ & 7,80 & 5,20 & 1,57 & 5,32 & 4,50 & 1,43 & 10,16 & 4,24 & 2,50 \\
\hline$S$ & 2,98 & 2,01 & 0,54 & 3,19 & 0,81 & 0,88 & 3,12 & 0,72 & 0,98 \\
\hline V & $38 \%$ & $39 \%$ & $34 \%$ & $60 \%$ & $18 \%$ & $61 \%$ & $31 \%$ & $17 \%$ & $39 \%$ \\
\hline As & 0,99 & 2,41 & 0,10 & 0,66 & 0,84 & $-0,10$ & $-0,29$ & 0,33 & 0,43 \\
\hline Ex & 0,95 & 6,09 & $-1,43$ & $-1,03$ & $-0,16$ & $-2,07$ & $-0,16$ & 0,71 & 0,28 \\
\hline
\end{tabular}

\section{DISCUSSION}

The analysis of the amplitude of the COG deviations in relation to the support area (Fig. 4.) shows that the highest average values for this parameter were found after the impact with balance asanas $(10.2 \mathrm{~cm})$ and in the initial measurement before yogic exercise ex- ecution $(9.4 \mathrm{~cm})$. The established average values and range are high, that means a low degree of balance stability. It is logical that the results of the initial measurement, which precedes the training impacts, fall into the "low balance stability" category. The data collected after performing the yogic asanas 
with a balance effect are illogical at first glance. The highest amplitude variations of the COG were recorded after yoga exercises, which in its specialization was closest to the dynamics of the control balance exercise. The explanation of the established negative motor transference is the assumption that the restorative processes of the neuromuscular apparatus after a training impact that is the same as the control effect is incomplete, despite the fact that the rest period between the different groups of yoga exercises is the same. This fact draws our attention on planning further studies to determine the regularities that characterize the optimal psycho-physiological conditions for achieving maximum high levels of balance stability.

The lowest average values of the COG amplitude variations were recorded after performance of asanas in dynamic mode $(5.3 \mathrm{~cm})$ and after asanas for relaxation $(5.7 \mathrm{~cm})$. This means that the impact of these exercises is the most beneficial for the balance abilities of performers. The existence of small amplitude deviations of the COG after performing yoga asanas with a relaxing effect can be considered logical. The explanation is that such effects activate the parasympathetic part of the nervous system. This leads to calming the participants, which is a favorable condition for better balance stability. The low values of the COG amplitude after performing asanas in dynamic mode provoke interest. There is a regularity according to which the dynamic exercises activate the sympathetic part of the nervous system to a greater degree. We believe that the physiological conditions resulting from such impacts stimulate the balance abilities as a result of increased muscle tone, which allows the better movement management.

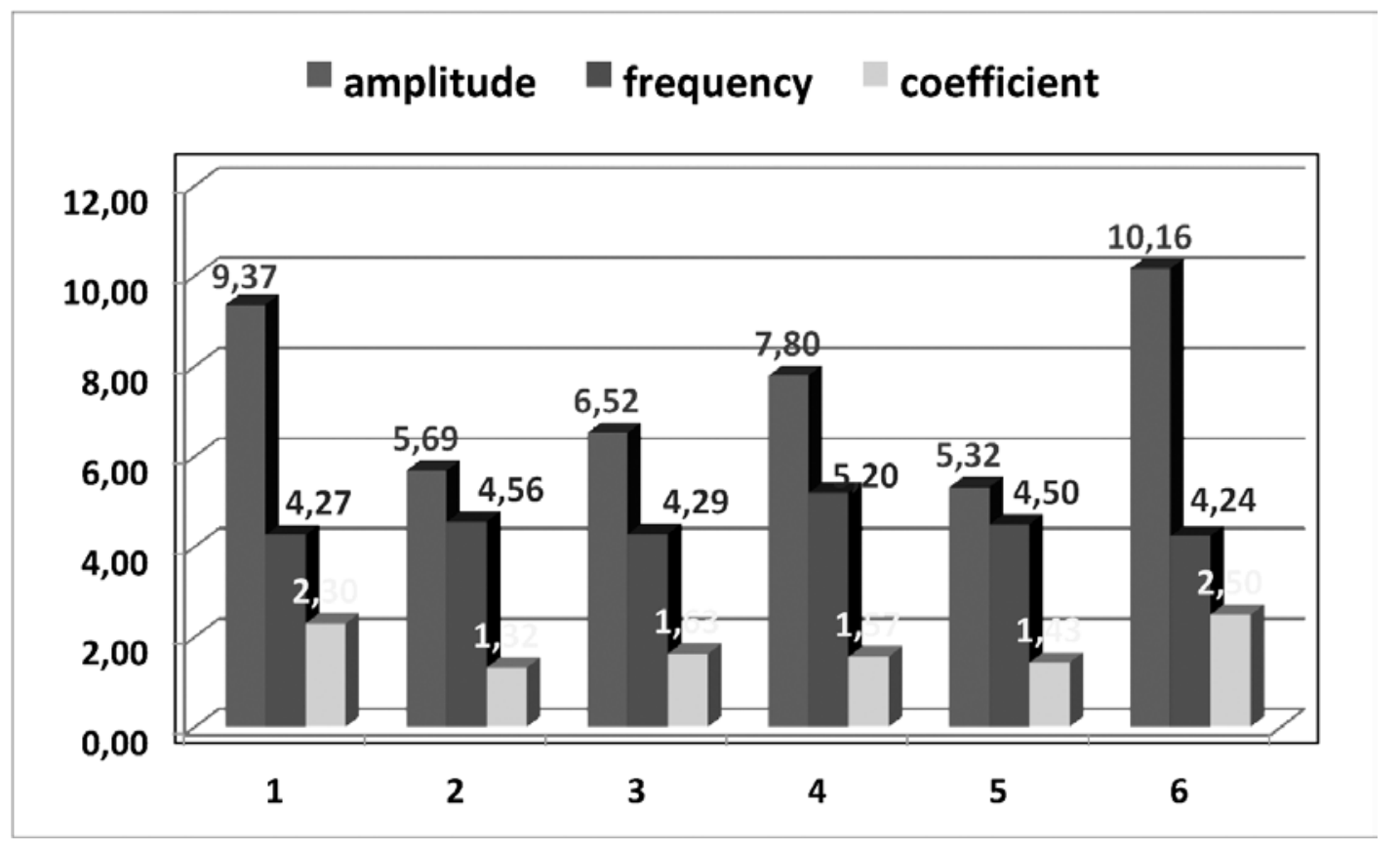

Figure 4. An average value of the established parameters during the conducted measurements 
The analysis of the frequency fluctuations of the COG can be defined as a relatively new characteristic associated with the balance stability study. The average values of this parameter established by this survey during the measurements are approximately the same. As mentioned above, this parameter gives information about internal efforts during the performance of the control balance exercise. The diagram in Fig. 4 shows that the fluctuations of the COG from the measurement after the performance of asana with stretching effect have the highest frequency. We believe that this finding does not constitute a sufficient enough reason for the data to be defined as regularity.

The balance coefficient, determined by the authors of this work, allows finding of the ratio between the amplitude deviation of the COG and its frequency fluctuations. This coefficient evaluates the balance abilities and synthesizes information about the shifting of the COG in relation to the support and the internal efforts of every participant. From the diagram in Fig. 4 it can be concluded that the registered values of this coefficient confirm the effects established by the COG amplitude deviations. The fact that deserves attention is the lowest value of the balance coefficient established during the measurement after the performance of the asanas with a relaxing effect. This gives reason to define this group of exercises as an impact that creates the most

\section{REFERENCES:}

Albert M. (2015). Kinzitrapevtichna progrma za podobriavane fizicheskata deesposobnost pri studenti sas zritelni narushenia. Dissertation

Bizzo G., Guillet M., Patat A. et al. favorable conditions for achieving a high level of balance stability.

\section{CONCLUSIONS}

The analysis of the results allows the following conclusions to be drawn:

The established average values of the three parameters (the amplitude of the COG deviations, the frequency fluctuations of the COG and the balance coefficient) allow to conclude that among the five test groups of yoga exercises the asanas for muscle release and those in dynamic mode have the most beneficial physiological effect on balance abilities.

The results from the study prove that performance of the balance asanas leave traces of reflections which impede the motor activity connected with balance abilities. This means that application of the balance asanas is not recommended immediately prior to balance exercises.

The unexpected results that have been identified focus our attention on planning future research to establish all regularities that determine the optimal psycho-physiological conditions for performing balance exercises.

The applied algorithm for processing the survey data is based on the principle of reading the registered amplitude variations of a given parameter. We believe that such an approach is applicable in analyzing similar processes in the study of kinematic and dynamometric parameters.

(1985). Specifications for building a vertical force platform designed for clinical stabilometry. Med. \& Biol. Eng. \& Comput., N23, pp. 474-476.

Farhi D. (2001). Yoga Mind, Body \& Spirit: A Return to Wholeness. Newleaf. 
Gagey P. M., Weber B. (1995). Posturologie. Regulation et dereglements de la station debout. Masson, Paris, pp. 145.

Gurfinkel V. S., Kots Y. M., Shik M. L. (1965). Regulation of man's posture. Nauka, Moscow.

Iyengar B. K. S. (1995). Light on Yoga: Yoga Dipika. Thorsons.

Kaminoff L, Matthews A. (2011). Yoga Anatomy - 2nd Edition. Human Kinetics

Kapteyn T. S., Bles W., Njiokiktjien Ch. J. et al. (1983). Standartization in platform stabilometry being a part of posturography. Agressologie, Vol.7., N24, pp. 321-326.
Long, R. (2009). The Key Muscles of Yoga: Scientific Keys, Volume I. Bandha Yoga Publications.

Long, R. (2009). The Key Poses of Yoga: Scientific Keys, Volume II. BandhaYoga.

Skvortsov D.V. (2000). Clinical analysis of movements. Stabilometry. AOZT Antidor, Moskow.

Smith, J., Hall, D., Gibbs, B. (2005). Yoga for everyone. Lorenz Books.

Stephens, M. (2010). Teaching Yoga: Essential Foundations and Techniques. North Atlantic Books.

Tishinov, O. et al. (1983). Stabilograph - AS №33600. Sofia

Correspondence:

Vladimir Angelov National Sports Academy "Vassil Levski", Sofia, Bulgaria E-mail: angelov.vl@gmail.com 